\title{
Mechanism of Pollutants Magnetized Biodegradation in Wastewater by Some Yeasts
}

\author{
Khalid Falih Hassan ${ }^{1}$, Noor Nihad Baqer ${ }^{2}$, Elaaf Safa Al-deen Hassan ${ }^{3}$ \\ ${ }^{1}$ BSc. Biology Scientific Research in Ministry of Science \& Technology $\backslash$ Environment \&Water Researches Dep., Iraq \\ ${ }^{2,3}$ Ministry of Science and Technology -Directorate of water and Environment, Baghdad, Iraq
}

\begin{abstract}
Magnetic field by 200, 300 and 400 gaos were selective to study their impacts on yeasts Candida dubliniensis ,Candida glabrata ,Issatchenkia orientalis and Rhodotorula mucilaginosa growth and to reduce organic pollutants in wastewater by COD, TOC, TN and TP in concentrations of 180, 75. 52 and 84 ppm in pH 7.6 and treatment periods of 2, 4, 6 and 18 hours in batch system. Results showed that magnetic field 300 gaos have higher ability to increase yeasts growth in 18 hours and reduce COD, TOC, TN and TP by 88, 85, 90 and 98.5\% in same period treatment. While, magnetic field 200 and 400 gaos have no effect on microorganisms growth and reducing organic pollutants.
\end{abstract}

Keywords: yeast, biodegradation, magnetized

\section{Introduction}

The main sources of pollution water bodies are the wastewater that is discharged into rivers without proper or partial treatment as it contains toxic organic substances that lead to a decline in natural water ; and disruption the balance of the environment which causes the occurrence of water pollution . Wastewater treatment processes rely on assimilation of microorganisms and enzymatic effectiveness in breakage chains carbon of soluble organic pollutants ; as sewage water contain many of the compounds aliphatic ,aromatic , phenolic compounds and toluene .Which are toxic and carcinogenic compounds. (Luz and Yoav, 2008).

Magnetic energy be an important role in the regulation of all forms life on the Earth's surface, and it has a very important role in regulating vital functions of all living organisms. Water significantly influenced by magnetic fields and composed of an atom of oxygen and two atoms of hydrogen, which gives it a polar character (bipolar charge ). Water molecule is not exist as individual molecule in nature but it is formation as cluster, it is smallest unit building for water that it size depend on the number molecules which are entering to formation of water clusters and associated bonds with one another. The magnetic field contributes on the rearrangement of the crystalline formation for water, which gives physical characteristic of water and it enable to penetrate the micro membranes faster through of orderly arrangement of molecules, as well as the magnetic field leads to increase the intra spacing of molecules and reduce the surface tension and thereby increase the solubility of oxygen (EPA, 2013).

The magnetic property of the water utilized physically to develop the effective techniques for treatment waste water by using a magnetic field including CoMag technique which uses to acceleration the sedimentation and Coagulation processes in waste water treatment plants, as well as BioMass technology uses different intensity of magnetic field to increase the amount of Bioflox and thus increase the efficiency of wastewater treatment plants, these techniques have been adopted on influence in physical characteristics of the materials suspended and clumping rapid by using magnetic technique (EPA, 2013) . This study aims to experiment a range of intensities magnetic field to increase the growth of Candida dubliniensis, Candida glabrata, Issatchenkia orientalis and Rhodotorula mucilaginosa and raise the efficiency biodegradation of organic pollutants in the wastewater.

\section{Material and Method}

\section{a) Collection and preparing Sampling}

Sample of waste water collected from precipitation of secondary stage Russtamyia Treatment Plant to treatment of waste water by using plastic bottles ( 5 liter for each one) transferred to laboratory .Samples filtered by vaccum pump and using nitrocellulose filter paper with pore size $0.45 \mu \mathrm{m}$ for experimentation .Other samples collected from waste water by sterile glass bottles(100 milliliter for each one ) for isolation and diagnosis bacteria and yeast.

\section{b) Chemical tests}

Concentration of oxygen demand (COD), total organic carbon (TOC), total phosphorus (TP) and total nitrogen (TN) were measured in waste water sample before and after treatment , adopted on a standard methods of analysis APHA (1998).

c) Isolation, cultivation and diagnosis of yeasts :

Yeasts isolated from waste water, PDA was prepared and added antibiotic chloramphenicol (prepared by dissolving $250 \mathrm{gm}$ from antibiotic to $250 \mathrm{ml}$ of D.W ) . One milliliter of sample was put in sterile plates and then PDA was added in plates that contain the samples .Plates were incubated in $27^{\circ} \mathrm{C}$ for 48 hour. Swabs were taken from each colony by using sterile loop for cultivating in new plates with PDA by streaking method then incubation in $27^{\circ} \mathrm{C}$ for 48 hour .After that, yeasts were diagnosed by biochemical tests according to the key classification (Kurtzman et al., 1998) ( Table 1). 


\section{International Journal of Science and Research (IJSR) ISSN (Online): 2319-7064 \\ Index Copernicus Value (2013): 6.14 | Impact Factor (2014): 5.611}

\section{d) Magnets}

The use of magnet dipole fig.( 1) that consists of two poles linked with a rod metal ,through which a degree of magnetic intensities is controlled by moving the poles to get the intensities required, a set of magnetic intensity was tested to choose the best of positive effect on reducing the concentration of pollutants in waste water and increase of microbial growth rates.

1) The magnetization effect on yeasts : Pure cultures of yeasts (Candida glabrata , Candida dubliniensis, Rhodotorula mucilaginosa and Issatchenkia orientalis) were used and grown in nutrient broth in volume $50 \mathrm{ml}$ by sterile glass bottles and the number of yeasts was counted via using of Hemocytometer before and after exposure to intensities of magnetic field 200, 300, 400 gaos.

2) Test precipitation of salting protein (salting out ) according to (David ,2009): The protein of milk was used for testing precipitation of salting protein to demonstrate the influence of a magnetic field on salt bridges, those which are linking of amino acids together and forming proteins . $100 \mathrm{gm}$ of powder protein was dissolved in $100 \mathrm{ml}$ of distilled water and ammonium chloride was added to reach for saturation up to $60 \mathrm{~g} /$ $100 \mathrm{~mL}$ of distilled water.

3) The experiment : Sample of wastewater was inoculated with yeast then it was exposed to intensities of magnetic field 200, 300, 400 gaos for period 2 , 4, 6, 18 hour and measured of factors which included biochemical COD, TOC,TP and TN for samples before and after magnetization as indicator of pollution. Sample has been chosen from waste water without magnetization as a control group ,which is measured in the same previous factors and the same period of intensities magnetic field.

\section{e) Calculations}

1) The cells number of yeasts was enumerated by Hemocytometer (counting chamber) )Prescott et al., 2002 ( according to equation :

2) The number of cell $($ cell $/ \mathrm{ml})=$ the number of cell in 4 squares $\times 4 \times 10$

Table 1: Biochemical tests for diagnosis of yeasts species in waste water

\begin{tabular}{|l|c|c|c|c|c|c|c|r|r|r|r|r|r|}
\hline Yeast species & \multirow{2}{*}{} & \multicolumn{10}{|c|}{ Sugar Assimilation } & \multirow{2}{*}{} \\
\cline { 3 - 13 } & $\mathbf{1}$ & 2 & 3 & 4 & 5 & 6 & 7 & 8 & 9 & 10 & 11 & 12 & $\mathbf{1 3}$ \\
\hline Candida dubliniensis & - & + & - & + & - & - & + & + & + & - & - & + & + \\
\hline Candida glabrata & - & + & - & - & - & - & - & - & - & - & - & - & - \\
\hline Issatchenkia orientalis & - & + & - & - & - & - & - & + & - & - & - & - & - \\
\hline Rhodotorula mucilaginosa & + & + & - & + & + & - & + & + & + & + & + & Weak & + \\
\hline
\end{tabular}

1-Urealysis. Sugar Assimilation: 2-Glucose 3-Inulin 4Sucrose 5-Raffinose 6-Lactose 7-Trehalose 8-Maltose 9-DXylose 10-D-Arabinose 11- L-Arabinose 12-Manitol 13Simon citrate.

\section{1- The magnetic field effect on the reduction of concentrations pollutants from wastewater}

Table (2) shows the reduction of pollutants from unsterile waste water by indicating of factors COD ,TOC,TN and TP during the period of 2,4,6 and 18 hour without treatment by magnetic field intensities, which considered as control . The concentrations factors of COD ,TOC,TN and TP were 180, 75, 52 and 84 ppm respectively .These values decreased, as COD value oscillated from 178-121 ppm . Whereas, TOC
3) Measurement of the cell size: measured size of yeast cells by method (Reynolds and Jaworski, 1978 ; Lund, 1958) through of the calibration ocular micrometer lenses of microscopic.

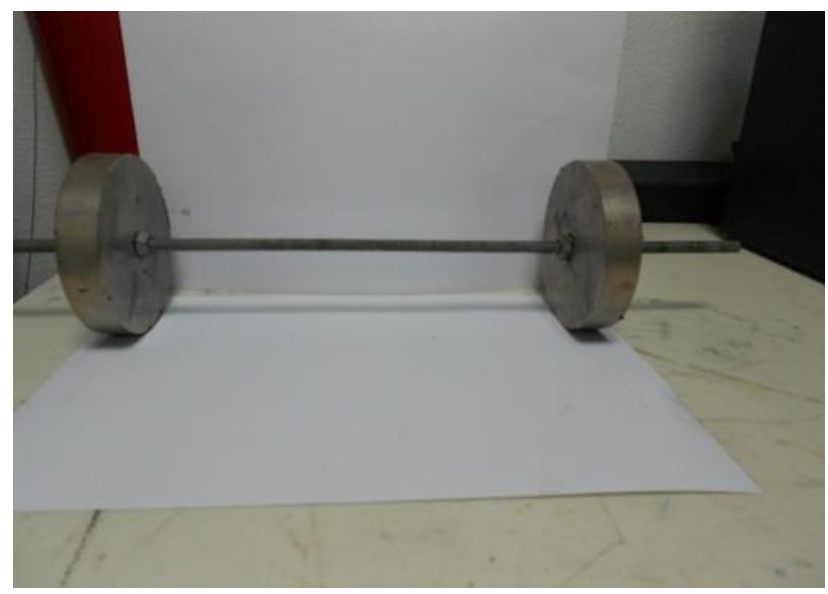

Figure 1: Dipole magnets used in the experiments

\section{Results and Discussion}

\section{Isolation and diagnosis of yeast}

Table (1) shows the results of biochemical tests for diagnosis yeasts Candida dubliniensis ,Candia glabrata, Issatchenkia orientalis and Rhodotorula mcilaginosa that isolated from waste water according to (Kurtzman et al., 2011) . Takashi et al.( 2008) in their study proved the presence of Candida dubliniensis and Candida glabrata in waste water. It has proven it is efficient in reducing concentration of phosphorous compound significantly . Shaym and Neelam(2008) demonstrated in their study isolated yeasts Candida dubliniensis and Candia glabrata from waste water the efficiency of these species in reducing concentrations of phosphorus and organic compounds.

\section{Volume 5 Issue 3, March 2016}




\section{International Journal of Science and Research (IJSR) \\ ISSN (Online): 2319-7064 \\ Index Copernicus Value (2013): 6.14 | Impact Factor (2014): 5.611}

Table (3) shows the reduction of pollutants from unsterile waste water by indicating of factors COD ,TOC,TN and TP during the period of 2,4,6 and 18 hour after treatment by intensity of magnetic field 300 gaos. The concentration of factors COD, TOC,TN and TP before magnetism was 180 , 75, 52 and 84 ppm respectively. These values decreased , as COD value oscillated from 168-22 ppm . Whereas, TOC value was from 72-11 ppm. While, TN value was ranged from 49-0.5 ppm . As for, TP value fluctuated from 83-1.2 ppm during the period of magnetization.

Table 3: Shows the reduction of pollutants by indicating of factors COD ,TOC ,TN and TP for waste water sample treated magnetically by 300 gaos for period the magnetization of 2, 4, 6 and 18 hours

\begin{tabular}{|r|c|c|c|c|l|}
\hline Test & $\begin{array}{c}\text { The concentration } \\
\text { before treatment } \\
\end{array}$ & \multicolumn{4}{|c|}{$\begin{array}{c}\text { The concentration after } \\
\text { treatment(ppm) }\end{array}$} \\
\cline { 3 - 6 } & $\mathbf{2 p m}$ & $\mathbf{4} \mathbf{h}$ & $\mathbf{6 ~ h}$ & $\mathbf{1 8 ~ h}$ \\
\hline COD & 180 & 168 & 152 & 120 & 22 \\
\hline TOC & 75 & 72 & 71 & 54 & 11 \\
\hline TN & 52 & 49 & 44 & 35 & 0.5 \\
\hline TP & 84 & 83 & 74 & 58 & 1.2 \\
\hline
\end{tabular}

The results of current study show high efficiency to magnetic field with intensity 300 gaos in the reduction of pollutants by indicating of factors COD ,TOC,TN and TP from waste water, as the rate of decline was 88, 85, 90, $98.5 \%$ respectively after 18 hour. Whilst, the rate of decline to the control group was 33, 23, 27, 24\% respectively. The result agreed with (Krzemieniewski et al., 2004) in their study on Dairy Wastewater and Domestic Sewage, it has been proven the efficiency magnetic field on reduction of COD , N-NH4 , P-PO4 at rate 55, 66 , $70 \%$ respectively . Glenn et al. (2011) proved the ability of magnetic field to reduce the concentration of pollutants in fresh water and sewage at high rates.

The magnetic field effects on the physical properties of water by reducing the surface tension to the watery body and hence the increase of the solubility of oxygen, which leads to increase aerobic oxidation processes .On the other hand, the magnetic field works to rearrange the molecules regularly, leading to increase in the spacing between them and the penetration of the necessary oxygen molecules for oxidative processes. It provides more space surface to microorganism for moving through the watery body for the occurrence biodegradation by enzymatic analysis (Štefušová et al., 2012) and (EPA, 2013).

Yeasts are of the microorganism that are efficient in biodegradation of organic pollutants in sewage water. Abdullahi et al. (2011) in their study showed the efficiency of Candida and Rhodotorula in reducing concentrations of pollutants and the use of these yeast in biofiltration with efficiently for more than $40 \%$,as well as, Woertz et al.( 2001) demonstrated the effectiveness of black yeast Exophiala lecanii-corni to eliminate of toluene from waste gas streams.The results of current study agreed with Coey and Cass( 2000) proved that the positive influences magnetic is affected by positive and negative ions and the amount of organic material . The effect is physically through the arrangement of molecules in the watery body and reduces the surface tension, so increase the solubility of oxygen, which leads to increase oxidative aerobic for organic and inorganic pollutants. As well as, the results compatibility with Rao and Omprakash(2013) proved in their study on the influence of magnetic field on waste water that the selection of the appropriate magnetic intensity had a significant positive impact in reducing the concentrations of pollutants, as well as proved that for each type of waste has the intensity of a magnetic effective affect depending on the concentration of salts, ions , organic matter, hydrocarbon and the nature of its molecular structure, and this has been proved by the current study. When using intensities magnetic 200 and 400 gaos on waste water there was no impact of effective these ratios and were reduced concentrations of pollutants approaching to the value of the control group (Figure 2).

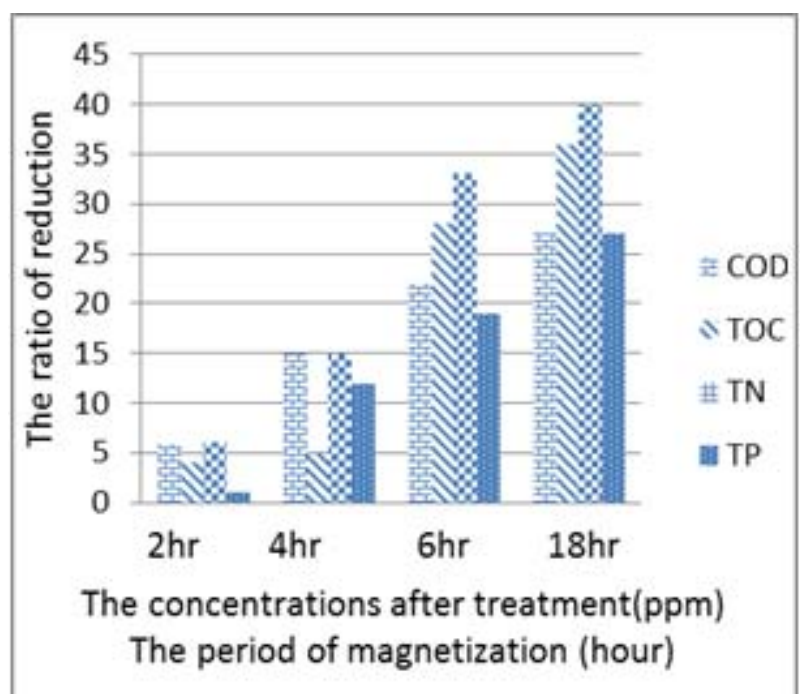

Magnetization 400 gaos

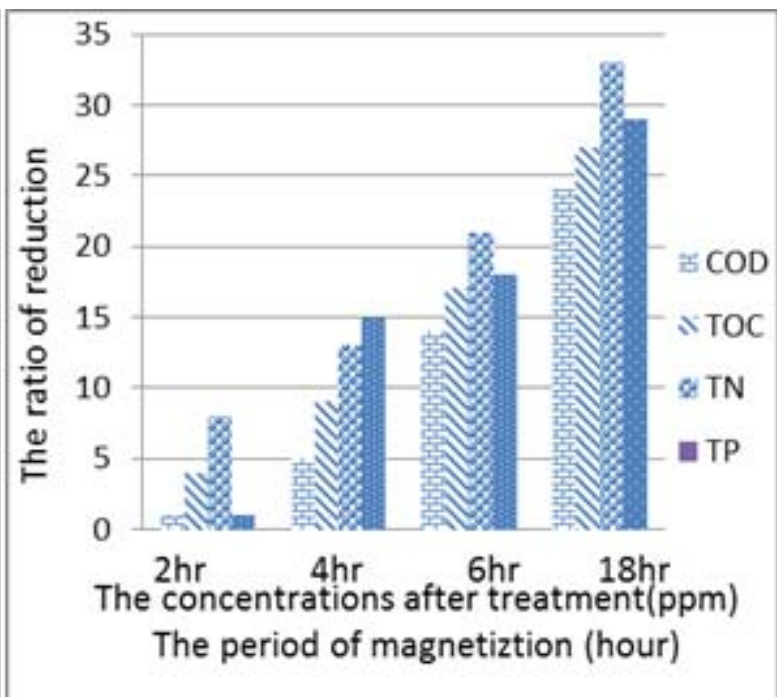

Magnetization 200 gaos

Figure 2: The ratio of reduction concentration of pollutants by indicating factors COD, TOC TN,TP in wastewater after treatment with intensities of magnetic field 200 and 400 gaos 


\section{International Journal of Science and Research (IJSR) \\ ISSN (Online): 2319-7064 \\ Index Copernicus Value (2013): 6.14 | Impact Factor (2014): 5.611}

Table(4 ) shows the effect of field magnetic with intensity 300 gaos on the growth of yeasts Issatchenkia orientalis, Rhodotorula mucilaginosa, Candida dubliniensis and Candida glabrata for a period of magnetization 2,4,6 and 18 hour . The number of yeasts were $40-50 \times 10^{4}$ cell $/ \mathrm{ml}$ before exposure to the intensity of the magnetic field . After magnetization the number of Issatchenkia orientalis increased to $56-200 \times 10^{4} \mathrm{cell} / \mathrm{ml}$ and Rhodotorula mucilaginosa increased to $65-2100 \times 10^{4}$ cell $/ \mathrm{ml}$, whilst the number of Candida dubliniensis 57-2700 $\times 10^{4} \mathrm{cell} / \mathrm{ml}$ .The increase was in the number of Candida glabrata 65 $2800 \times 10^{4} \mathrm{cell} / \mathrm{ml}$ compared with control group through period of magnetization.

Table 4: Shows the effect of intensity magnetic field 300 gaos on growth of yeasts Candida galbrata 'Issatchenkia orientalis , Rhodotorula mucilaginosa and Candida dublinisis after 2,4,6,18 hour magnetization.

\begin{tabular}{|c|c|c|c|c|c|}
\hline Yeast & $\begin{array}{c}\text { The number } \\
\text { of cell before } \\
\text { magnetization } \\
\times(\text { cell /ml })\end{array}$ & \multicolumn{4}{|c|}{$\begin{array}{c}\text { The number of cell } \\
\text { after magnetization } \\
\text { (cell /ml ) }\end{array}$} \\
\cline { 3 - 7 } & $10^{4}$ & $\mathbf{2 h}$ & $\mathbf{4 h}$ & $\mathbf{6 h}$ & $18 \mathrm{~h}$ \\
\hline Issatchenkia orientalis & 45 & 56 & 87 & 350 & $\mathbf{2 0 0 0}$ \\
\hline Control & 43 & 50 & 65 & 70 & $\mathbf{1 2 0}$ \\
\hline Rhodotorula mucilaginosa & 50 & 65 & 90 & 320 & $\mathbf{2 1 0 0}$ \\
\hline Control & 48 & 55 & 68 & 78 & $\mathbf{1 3 0}$ \\
\hline Candida dubliniensis & 40 & 57 & 75 & 315 & $\mathbf{2 7 0 0}$ \\
\hline Control & 45 & 55 & 62 & 80 & $\mathbf{1 6 0}$ \\
\hline Candida glabrata & 48 & 65 & 95 & 360 & $\mathbf{2 8 0 0}$ \\
\hline Control & 48 & 60 & 75 & 90 & $\mathbf{1 6 5}$ \\
\hline
\end{tabular}

It proved the results of the current study. The large positive effects to the intensity of the magnetic field 300 on
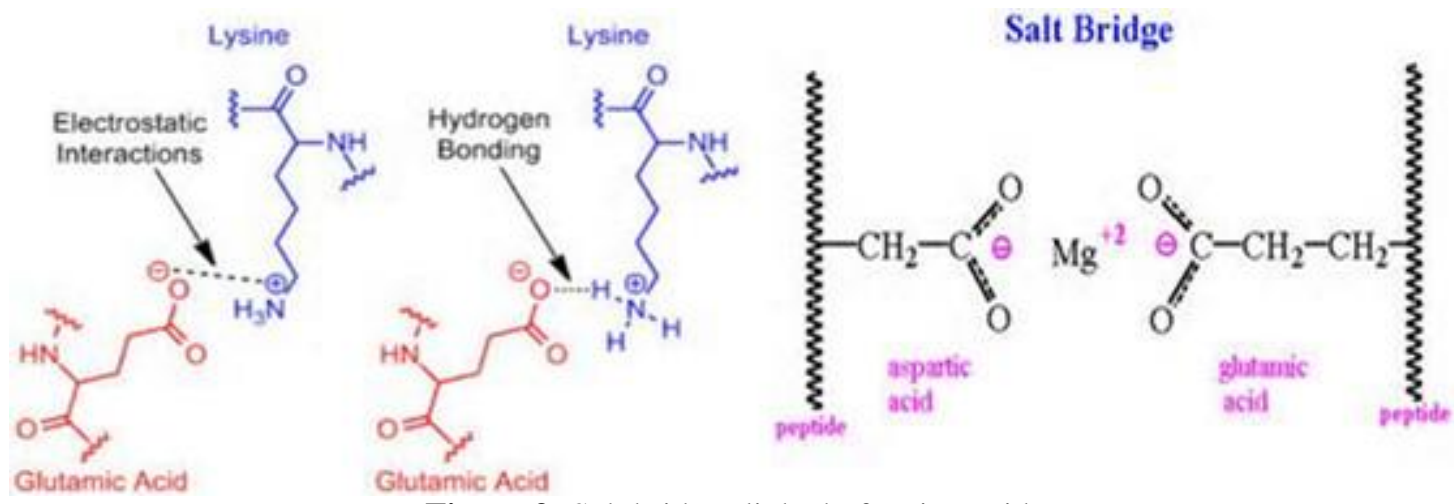

Figure 3: Salt bridges linked of amino acids

Salt bridges and electrostatic forces that linked of amino acids influenced by the intensity of magnetic field when using of intensity of magnetic field 300 gas, so the Salt bridges and electrostatic forces lead to dilation of bacterial cell or yeast therefore, the size pore in cell wall will expand ; thereby, this will increase the exchange of materials between the organism and its surroundings. This leads to increase in cellular metabolism and raise in the growth. Whilst the using of intensity magnetic 200 , 400 goas that the salt bridges break , thus the cellular wall degrades and causes killing of bacteria , this was confirmed by test (salting out) .as the precipitation of protein in control sample however, in the magnetization sample do not occur sedimentation ,this indicate that the intensity of magnetic field affect the salt bridges bond increasing the growth of microorganism in waste water, as well as , the pure culture of bacteria and yeast, The results of this study do not correspond to the local and international studies. It is the first recording of the efficiency of the magnetic field in the increased growth of microorganisms and the interpretation of this positive impact. Scientific research has focused on the use of magnetic intensity to kill microorganisms and prevent their growth as in the study (Kohno et al., 2000 ; Ceon and Martin, 2005 ; Banejad and Abdosalehi, 2009 ; Morteza et al., 2012).

The cell wall of the microorganisms as yeast is composed of polysaccharides and protein with some differences with some of the differences in thickness of the layers and the quality of the polysaccharide and amino acids of the protein constituent (Lapidus et al.,2000) . Kim and Giovanni(2005) proved that the protein layers located within the cell wall are composed of amino acids group (Alanine, Glycine, Leucine, Valine, Treptophan, Isoleucine) that are bipolar because of their terminal groups within the molecular structure as positive amino group $\mathrm{NH}_{4}$ and a negative carboxyl COO - . Proved William et al.(2010) the presence of lipopolysaccharides and peptidic polysaccharides ,that are dipolar via the presence of nitrogen , phosphor and groups of carboxyl. (Li and Wingreen, 1997) demonstrated that the amino acids are linked with each other and with layer of polysaccharides within the cell wall via hydrogen bonds and salt bridges, that are linking amino acids together by electrostatic force ( Figure 3). 


\section{International Journal of Science and Research (IJSR) \\ ISSN (Online): 2319-7064 \\ Index Copernicus Value (2013): 6.14 | Impact Factor (2014): 5.611}

of concentrations salt are proportional with the magnetic effects.

\section{Conclusions}

1) The intensity of magnetic field 300 gaos has large positive effects on increasing the growth of bacteria, yeasts and reducing the concentrations of pollutants in wastewater at high rates.

2) The intensity of magnetic field 200 and 400 gaos showed efficient approach to control and did not have a positive impact on the growth of microorganisms or reducing the concentration of pollutants in wastewater.

\section{References}

[1] Luz, E. B. and Yoav, B. (2008). Recent advances in removing phosphorus from wastewater and its future use with activated sludge. Water Research 38: 4222-4246.

[2] U.S.A Environmental Protection Agency (2013). Emerging Technologies for Wastewater Treatment and In-Plant Wet Weather Management. Office of Wastewater Management U.S. Environmental Protection Agency Washington, D.C.

[3] APHA (1998). Standard method for the examination of water and wastewater, $16^{\text {th }}$ ed. American public Health Association, American water works Association and water pollution control federal, Washington, D.C.

[4] Kurtzman, C.P.; Fell, J.W and Boekhout, T. (1998).The yeasts: a taxonomic study 5 thed. Elsevier Science B.V.:230-234,252-253,268-269.

[5] Prescott, L.M.; Harly, J.P. and Klien, D.A. (2002). Microbiological. $5^{\text {th }}$ ed- London. MC Graw Hill companies.

[6] Reynolds, C.S. and Jaworski G.H. (1978). Enumeration of natural Microcystis populations. British Phycological Journal. Vol. 13 : 1269-277.

[7] Lund, J.W.; Kipling, G. and Le Cren, E.D. (1958). The inverted microscope method of estimating algae numbers and the statistical basis of estimation by counting. Hydrobiologia. Vol. 11: 143-170.

[8] David, Sh. (2009). Physical biochemistry. Wiley Blackwell. Cambridge press.Uk. p 285.

[9] Kurtzman, C.P.; Fell, J.W and Boekhout, T. (2011).The yeasts: a taxonomic study 5 thed. Elsevier Science B.V.:230-234,252-253,268-269.

[10] Takashi, W.; Noriatsu, O.; Kazuhiro, I.; Tsutomu, F. and Haruyuki, I. (2008). Breeding of wastewater treatment yeasts that accumulate high concentrations of phosphorus. Appl. Microbiol Biotechnol. Vol. 80:331338.

[11] Shaym, S. and Neelam, S. (2008). Use of polyphosphate Accumulating organisms for treatment of phosphate sludge. Proceeding of Taa2007: The $12^{\text {th }}$ world Lake conference India : 918-922.

[12] Krzemieniewski, M.; Dębowski, M.; Janczukowicz, W. and Pesta, J. (2004). Effect of the Constant Magnetic Field on the Composition of Dairy Wastewater and Domestic Sewage. Polish Journal of Environmental Studies. Vol. 13.Pp: 45-53.

[13] Glenn. F. Cada; Mark, S. Bevelhimer; Kristina, P. Riemer and Julie, W. Turner (2011). Effects on freshwatr organisms of magnetic field associated with hydrokinetic turbines. Annual Report. Oakridge national laboratory Oak Ridge, Tennessee. USA.

[14] Štefušová1, K.; Václavíková, M.; Lovás, M. and Hredzák, S. (2012). Use of magnetic filtration in waste water treatment. Acta Montanistica Slovaca. Vol. 17. Pp: 81-84.

[15] Abdullahi, B. R; Lami, I.; Udeme, J.; Ijah, J. and Shu'aibu, B. M. (2011). Assessment of the efficiency of a yeast biofilter in the treatment of wastewater. African Journal of Biotechnology. Vol. 10. Pp: 93479351.

[16] Woertz, J.R.; Kinney, K.A.; McIntosh, N.D.P. and Szanisab, P.J. (2011). Removal of toluene in a Vapour phase bioreactor containing a strain of the dimorphic black yeast Exophiala lecarnii-cornii. Biotechnol. Bioeng. Vol. 75. Pp: 550-558.

[17] Rao, M. Srinivasa and Omprakash, S. (2013). Study of Electromagnetic Waves on Industrial Waste Water. Physics and Materials Chemistry. Vol. 1. Pp: 34-40.

[18]Kohno, M.F.; Yama, Z.A.; Kimura, I. and Wafa, M.C. (2000). Effect of static magnetic field on bacteria streptococcus mutans and Escheriachia coli. J Am pathophysiology. Vol. 17: 143-148.

[19] Ceon, R. and Martin, J.T. (2005). low- level, magnetic field induced growth modification of Bacillus subtilis. J Bioelectromagnetics. Vol. 8 (3):275-282.

[20] Banejad, H. and Abdosalehi, E. (2009). The effect of magnetic field on phosphate pollutants compounds in wastewater. Thirteenth International Water Technology Conference, IWTC 13 2009, Hurghada, Egypt.

[21] Morteza, H.; Mohammad, J. M.; Mohammad, B. and Saman, S. (2012). EFFECT OF STATIC MAGNETIC FIELD ON Bacillus Growth. International Journal of Advanced Biotechnology and Research. Vol. 3: 777 781.

[22] Lapidus, L.; Eaton, W. and Hofrichter, J. (2000). Measuring the rate of intromolecular contact formation in polypeptides. Proc. Natl. Acad. Sci. Vol. 97:72207225.

[23] Kim, S. and Giovanni, Z. (2005). Physics in molecular biology. Cambridge press.Uk. Pp:80-90.

[24] William, H.; Christopher, S.; Brent, L.; Eric, V. and Bruce, M. (2010). Organic chemistry. Sixth edition. Cengage learning international. China. Pp:1101-1110.

[25] Li, H. and Wingreen, N.S. (1997). Nature of driving force protein folding: a result from analyzing the statistical potential. Phys. Rev. Lett. Vol. 79:765.

[26] Iwasaka, M. and Ueno, S. (1998). Structure of water molecules under $14 \mathrm{~T}$ magnetic field. Appl. Phys. Vol. 83(11):6459.

[27] Coey, J.M.D. and Cass, S. (2000). Magnetic water treatment. Magnetism and magnetic materials. Vol. 209:74.

[28]Feug, P.X. (2008). The changes of macroscopic features and microscopic structures of water under influence of magnetic field. Elsevier, physics. Vol. 403:357-361. 